\title{
La disartria desde la interacción entre Logopedia y Fonética acústica. Seguimiento y rehabilitación para la obtención de una "voz funcional"
}

\author{
Carmen Castillo Requena \\ Hospital Universitario Puerto Real \\ Carretera Nacional IV, Km. 665 \\ 11510 Puerto Real (Cádiz) \\ E-mail: mccasreq@yahoo.es
}

\author{
MARÍA Dolores MuÑoz NúÑEZ \\ Universidad de Cádiz \\ Facultad de Filosofia y Letras \\ Avda Dr. Gómez Ulla s/n \\ 11003 Cádiz \\ E-mail: mdolores.munioz@uca.es
}

\begin{abstract}
LA DISARTRIA DESDE LA INTERACCIÓN ENTRE LOGOPEDIA Y FONÉTICA ACÚSTICA. SEGUIMIENTO Y REHABILITACIÓN PARA LA OBTENCIÓN DE UNA "VOZ FUNCIONAL"
\end{abstract}

RESUMEN: Este trabajo pretende mostrar los beneficios que aportan dos métodos utilizados habitualmente en Logopedia para, entre otras patologias, la disartria: el método del acento y lax vox. También quiere hacer hincapié en que, cuando el logopeda emprende una labor de rehabilitación, no busca una voz normal sino una "voz funcional". Entendemos por funcional aquella que le permite a la persona un desempeño adecuado en las diferentes situaciones de comunicación. Al mismo tiempo exponemos que el análisis acústico se revela como la herramienta de medición más objetiva del progreso rehabilitador en disartria. Frente a lo realizado hasta el momento, en que se tiene en cuenta sólo el pitch de una vocal, presentamos -a partir de algunos casos prácticos- el análisis de otros parámetros, como la frecuencia de los demás armónicos, la amplitud y el tiempo, que nos proporcionan datos muy relevantes sobre la progresión de la curva melódica y del habla en general del paciente.

PALABRAS CLAVES: disartria; voz funcional; métodos en logopedia; análisis acústico; Praat.

SUMARIO: 1. La disartria y sus patologias. 2. Técnicas en Logopedia. La consecución de una "voz funcional". 3. Presentación de algunos casos clínicos. 4. ¿Se puede generar una técnica de análisis acústico a partir de unos patrones sobre los que incidir? 5. Conclusiones.
DYSARTHRIA FROM THE INTERACTION BETWEEN SPEECH THERAPY AND ACOUSTIC PHONETICS. MONITORING AND REHABILITATION TO OBTAIN A "FUNCTIONAL VOICE"

ABSTRACT: This paper aims to show the benefits of two methods commonly used in speech therapy for, among other pathologies, dysarthria the accent and the voice method. It also wants to emphasize that, when the speech therapist undertakes a rehabilitation work, he does not look for a normal voice but a "functional voice". We understand by functional those that allows the person an adequate performance in different communicative situations. At the same time, we show that acoustic analysis is revealed as the most objective measurement tool of rehabilitation progress in dysarthria. In contrast to what has been done so far, in which only the pitch of a vowel is taken into account, we present -from some practical cases- the analysis of other parameters, such as the frequency of the other harmonics, amplitude and time, which provide us with very relevant data on the progression of the melodic curve and speech of the patient in general.

KEY WORDS: dysarthria; functional voice; methods in speech therapy; acoustic analysis; Praat.

SUMMARY: 1 . Dysarthria and its pathologies. 2. Speech Therapy Techniques. The achievement of a "functional voice". 3. Presentation of some clinical cases. 4. Can an acoustic analysis technique be generated from some patterns on which to influence? 5 . Conclusions.
DYSARTHRIE DE L'INTERACTION ENTRE L'ORTHOPHONIE ET LA PHONETIQUE ACOUSTIQUE. SUIVI ET RÉHABILITATION POUR OBTENIR UNE "VOIX FONCTIONNELLE"

RÉSUMÉ: Cet article a pour but de montrer les avantages de deux méthodes couramment utilisées en orthophoni pour traiter, entre autres pathologies, la dysarthrie: la méthode de l'accent et la lax vox. Il tient également à souligner que, lorsque l'orthophoniste entreprend un travail de réadaptation, il ne recherche pas une voix normale mais une "voix fonctionnelle". Nous comprenons fonctionnel ce qui permet à la personne une performance adéquate dans différentes situations de communication. $\mathrm{Au}$ même temps, nous montrons que l'analyse acoustique se révèle l'outil de mesure le plus objectif de progrès de la rééducation dans la dysarthrie. Contrairement à ce qui a été fait jusqu'à présent, où seulement on tenait en compte le ton d'une voyelle, nous présentons -à partir de cas practiquesl'analyse d'autres paramètres, tels que la fréquence des autres harmoniques, l'amplitude et le temps, qui nous fournissent des données très pertinentes sur la progression de la courbe mélodique et de la parole en général du patient.

MOTS CLÉS: dysarthrie; voix fonctionnelle; méthodes en orthophonie; analyse acoustique; Praat.

SOMMAIRE: 1 . La dysarthrie et se pathologies. 2. Techniques d'orthophonie. La réalisation d'une "voix fonctionnelle". 3. Présentation de quelques cas cliniques. 4. Une technique d'analyse acoustique peut-elle être générée à partir de certains modèles sur lesquels faire attention? 5. Conclusions. $\begin{array}{ll}\text { Fecha de Recepción } & 05 / 02 / 2019 \\ \text { Fecha de Revisión } & 28 / 02 / 2019 \\ \text { Fecha de Aceptación } & 10 / 05 / 2019 \\ \text { Fecha de Publicación } & 01 / 12 / 2020\end{array}$

DOI: http://doi.org/10.25267/Pragmalinguistica.2020.iextra2.04 


\title{
La disartria desde la interacción entre Logopedia y Fonética acústica. Seguimiento y rehabilitación para la obtención de una "voz funcional"
}

\author{
Carmen Castillo Requena \& María Dolores MuÑoz NúÑEZ
}

\section{LA DISARTRIA Y SUS PATOLOGÍAS}

La comunicación es una de las funciones más complejas que cumple el ser humano. Son muchos los procesos que ocurren cuando hablamos, pero se pueden dividir en dos tipos: los procesos de tipo cognoscitivo y lingüístico y los procesos que permiten el control sensoriomotor de la musculatura que interviene en la producción oral.

Podemos entonces definir la disartria como una alteración del habla originada por una lesión que afecta al sistema nervioso central y/o periférico. El origen de dicha lesión puede ser multicausal (ACV de tipo isquémico, hemorrágico, traumatismo cráneo-encefálico, lesiones por infección, o por trastornos de tipo neurodegenerativo). El paciente con disartria presentará una alteración motora o del control motor del movimiento que impide la normal ejecución en el habla.

Según Melle (2007a: 13-14):

la disartria es una afectación neurológica del sistema nervioso central y/o periférico que produce dificultades en la programación o la ejecución motora dando lugar a la presencia de alteraciones en el recorrido muscular, la fuerza, el tono, la velocidad y la precisión de los movimientos realizados por la musculatura de los mecanismos que participan en la producción, esto es, en la respiración, fonación, la articulación y la resonancia.

Darley et al. (1975) establecieron además una clasificación actualmente aceptada en seis tipologías: disartria fláccida, espástica, hipocinética, hipercinética, atáxica, mixta, a las que se ha añadido una más, la disartria unilateral de la neurona motora superior.

Para llevar a cabo el tratamiento logopédico de las alteraciones que presenta el habla de un paciente con disartria es necesario un método de evaluación global que ponga de manifiesto la ejecución anómala por parte del paciente y que permita elaborar un plan de tratamiento adecuado.

La valoración se inicia con una entrevista que nos permita recabar información sobre la influencia de las dificultades en la comunicación, entrevista con la que podremos establecer la severidad y si se han desarrollado conductas de compensación. Ya en este momento observamos las dificultades motoras en la ejecución del habla, alteraciones en la velocidad, la fuerza, la coordinación y la presencia de movimientos incontrolados.

Para la exploración de los rasgos del habla nos basamos en la observación de aspectos auditivos y visuales (Melle, 2007b). Sin embargo, no existe un protocolo de evaluación en español, por lo que utilizamos el Dysarthria Profile de Robertson (1982), que ha sido traducido a nuestro idioma. Consta de 
8 apartados que evalúan la respiración, la fonación, la musculatura facial, la diadococinesis, los reflejos, la articulación, la inteligibilidad y la prosodia.

Para medir la inteligibilidad del habla en el paciente disártrico usamos la Escala de Inteligibilidad para Alteraciones Motoras del Habla (Intelligibility rating scale for motor speech disorders), que nos permite establecer en qué forma está afectada la comprensión del mensaje por un interlocutor. Presenta valores desde 1 cuando "el habla no es un medio viable de comunicación..." hasta 10 cuando el habla es "normal en todos los ambientes sin restricciones" (Duffy, 2005).

Melle (2007) hace una revisión de los instrumentos de evaluación utilizados en disartria, afirmando que "en nuestro país, la evaluación se centra frecuentemente en la exploración de las funciones de los pares craneales implicados en el habla, y en pocas ocasiones se recurre al empelo de instrumentos cuantitativos". Frecuentemente la causa es de orden económico y además estos instrumentos no están comercializados en nuestro territorio.

Por otro lado, una revisión presentada por Sellars et al. de la eficacia del tratamiento logopédico en adultos con disartria concluyen que "no existen pruebas de calidad que refuten la efectividad de la terapia del habla y del lenguaje para la disartria" (Sellars et al., 2007: 2).

La exploración de los rasgos acústicos del habla nos permite hacer una medición objetiva y cuantitativa de áreas de producción del habla, en función de dirigir los esfuerzos de planificación a las áreas afectadas y poder objetivar la progresión durante el tratamiento.

\section{TÉCNICAS EN LOGOPEDIA. LA CONSECUCIÓN DE UNA "VOZ FUNCIONAL"}

Existen en el mercado varios instrumentos para llevar a cabo el registro de la voz, como el MultiSpeech, el Visi-Ptich III y el CSL, y otros que permiten hacer valoración de parámetros como la frecuencia fundamental, la presencia o no de formantes y su transición o la capacidad articulatoria. Estos programas, si bien son muy útiles y nos dan mucha información, resultan muy caros y habitualmente el logopeda no dispone de ellos. El Praat es un programa de análisis acústico de la voz que puede descargarse de forma gratuita. Permite la valoración de parámetros acústicos del habla suficientes para obtener información cuantitativa y objetiva del estado y el progreso del habla y la voz de un paciente durante el tratamiento.

La crítica que habitualmente se hace a estos instrumentos viene determinada por la ausencia de estandarización que permita establecer datos de normalidad y de patología.

En lo referente exclusivamente a valoración de la voz, Cobeta et al. (2013: 237) dicen que "por naturaleza, la variedad de voces es ilimitada y los estándares que cumple una voz adecuada son amplios. El concepto de voz normal, con criterios objetivos y absolutos, no existe". Por su parte Moore (1971: 8) afirma que "no existe una forma única de sonido que podamos llamar voz normal". Las variabilidades de las voces serán influenciadas por 
parámetros como la edad (bebé, niño, adulto, anciano), el sexo, el lugar geográfico, la cultura, la situación social (uso diferente de habla y voz en un ambiente festivo que en un sepelio, en un Congreso que en una reunión familiar), la educación y la formación en técnica vocal (un actor de teatro o un locutor de radio).

Aronson (1990) expone los criterios generales sobre la voz normal. Considera que una voz normal debe tener un timbre agradable, un tono, volumen y flexibilidad apropiados. Por tanto, considera que hay un trastorno de la voz cuando su timbre, tono, intensidad o flexibilidad difieren de las de las voces de las demás personas del mismo sexo, edad y grupo cultural. ¿Por qué entonces algunos de estos pacientes no sienten que tengan una disfonia?

La cuestión entonces es ¿cómo medir todos esos parámetros para lograr una valoración cuantitativa y objetiva que permita al logopeda establecer si la progresión del tratamiento es adecuada, si no disponemos de criterios de normalidad?

En el proceso de comunicación hay un emisor -en este caso el pacienteun receptor -el interlocutor- y el mensaje emitido. Al intentar medir solo la ejecución de voz y habla del paciente, estamos objetivando solo una parte del proceso de comunicación, estamos midiendo el mensaje. Para completar la evaluación debemos medir también cómo percibe la ejecución cada uno de los protagonistas de la comunicación, cómo se siente en dicho proceso, tanto el emisor como el receptor.

Nosotros proponemos estudiar el proceso de comunicación completo, no solo el habla del paciente disártrico. Utilizaremos para ello, por un lado, el análisis acústico de la voz y el habla, como medida del mensaje, pero no para compararlo con la normalidad, puesto que esta en realidad no existe, sino para estudiar la progresión de su voz y su articulación comparándose consigo mismo al inicio del tratamiento y progresivamente, durante y al final del mismo. Esto nos dará valores cuantitativamente medibles y objetivables.

Pero, para valorar el proceso completo de comunicación, no es suficiente con estos valores, puesto que no existen criterios de normalidad. Podemos averiguar si, de cara al proceso de comunicación, para el paciente son suficientes, si le resultan útiles.

En cuanto al emisor (paciente) utilizamos un cuestionario satisfacción (Voice Handicap Index), en el que el propio paciente valora su producción vocal en aspectos funcionales, físicos y emocionales.

En cuanto al receptor (interlocutor), veremos si la comunicación es efectiva mediante el cuestionario de la inteligibilidad del habla con la escala de inteligibilidad de Duffy (2005). Ello nos permite revisar cada uno de los elementos que intervienen en la comunicación: el mensaje, el emisor y el receptor, en términos de comunicación efectiva, que en definitiva es el objetivo fundamental de la terapia logopédica que enfrenta la rehabilitación de pacientes con trastornos de voz en disartrias. 
Por ello proponemos la búsqueda de un habla y una voz funcionales, no normales. La funcionalidad la podemos establecer en aras de la mejora de los parámetros medibles con el análisis acústico, complementado con el resultado de los cuestionarios de satisfacción del paciente (emisor) y de la escala de inteligibilidad que realiza el interlocutor (receptor).

Una vez hecha la valoración, el logopeda propone un plan terapéutico dirigido a la mejora de las áreas alteradas. Nos basamos para ello en el modelo conceptual de salud elaborado por la Organización Mundial de la Salud (OMS), tal y como propone Worrall (2000). Este modelo permite una visión integradora y multidimensional de la persona y de cómo la alteración (disartria) influye en su desempeño diario. Se describe en la Clasificación Internacional del Funcionamiento de la Discapacidad y de la Salud (CIF-2000) y permite utilizar un lenguaje estandarizado y unificado para describir los estados de salud, con un sistema de codificación específico.

Afrontamos el plan terapéutico, según este modelo, atendiendo a: a) deficiencia estructural-corporal de la musculatura implicada en el habla; b) deficiencia funcional resultante, mejora de la producción vocal, reducción de la inteligibilidad, la velocidad de habla y los aspectos prosódicos, y c) limitación de la habilidad comunicativa dentro de un contexto social.

La disartria se manifiesta con grados de severidad, con unos signos y síntomas muy heterogéneos, variando mucho de unos pacientes a otros. Por ello el plan de intervención debe ajustarse a la valoración y las necesidades de cada paciente en concreto.

\section{Presentación de algunos casos clínicos}

Presentamos tres casos de disartria. Como ya dijimos anteriormente, la disartria presenta una variabilidad de manifestaciones que son diferentes en cada paciente. Por ello el planteamiento del tratamiento de rehabilitación es individual y ajustado a cada paciente.

PACIENTE 1: A. C., de 69 años, natural de Puerto Real (Cádiz), comerciante de profesión y con nivel medio de estudios (Educación Secundaria). Ingresa en nuestro hospital en julio de 2016 por alteración motora del lenguaje, con comprensión conservada, que se acompaña de dolor torácico y disnea de reposo. Había presentado en febrero de 2015 un hematoma cerebeloso y está siendo seguido en cardiología por insuficiencia cardiaca.

Tras estudios radiológicos con arteriografia se evidencia lesión cortical y subcortical localizada en zona temporal y parietal derecha compatible con lesión isquémica aguda-subaguda en territorio de arteria cerebral media.

Cuando el paciente ha sido estabilizado, presentando eupnea en reposo con gasometría dentro de la normalidad, es valorado por FEA de Medicina Física y Rehabilitación. Test de Pfeiffer con máxima puntuación, sin sospecha de deterioro cognitivo. Ha mejorado la articulación, conserva los procesos de lectura, comprensión y escritura dentro de la normalidad. Mantiene 
alteración de la expresión oral con habla entrecortada y cansancio frecuente con sensación de falta de aire. No presenta otras alteraciones motoras. Es diagnosticado de disartria y derivado a logopedia en agosto de 2016 para su tratamiento.

Valoración logopédica. Test de Robertson:

- Respiración y fonación: respiración torácica superior, casi clavicular, y con inspiraciones y espiraciones muy cortas. Tiempo Máximo de Fonación muy alterado. $A=2 \mathrm{sg}, \mathrm{S}=5 \mathrm{sg}$, con sensación de falta de aire. Voz constreñida, con habla entrecortada, y colapso durante la producción vocal. No se logra que haga cambios de tono porque no puede mantener el tono durante más de 2 ó 3 segundos.

- Diadococinesias: difícil ejecución, entrecortado y arrítmico.

- Musculatura facial, reflejos y articulación dentro de valores normales.

- Prosodia: muy alterada, no mantiene el ritmo de habla, es entrecortada y con sensación disneica. Severa incoordinación fonorrespiratoria.

Voice Handicap Index de Jacobson (1997): Funcional: 36, Físico: 25, Emocional: 22 .

Escala de Inteligibilidad de Alteraciones Motoras del Habla (Duffy, 2005): Nivel 5: usualmente reducida bajo condiciones adversas, cuando el contenido no tiene restricciones, aun cuando se intenta realizar reparos.

\section{Análisis acústico previo:}

En el análisis que se realiza -mediante el programa Praat- antes del tratamiento (sesión del 14.09.2016) se observa que el paciente presenta, como resultado de un problema de respiración, una curva melódica entrecortada por largas pausas -aunque un tiempo breve en la emisión de los sonidos-, una intensidad baja (60.33 dB en la [á] de levanto, que tomamos como referencia), pero, a pesar de cierta rigidez muscular, una conformación formántica cuyos valores corresponden más o menos a la media (los valores del F1 de [e]: $606.5 \mathrm{HZ}$, de [á]: $759.8 \mathrm{HZ}$ y de [o]: $431.3 \mathrm{HZ}$ ). En cuanto a consonantes teóricamente fuertes en la palabra levanto, la oclusiva [t], ligeramente fricatizada, presenta una pequeña barra de explosión y la fricativa [ $\beta$ ] es muy breve, aunque, salvo la duración, no hay nada relevante en su pronunciación:

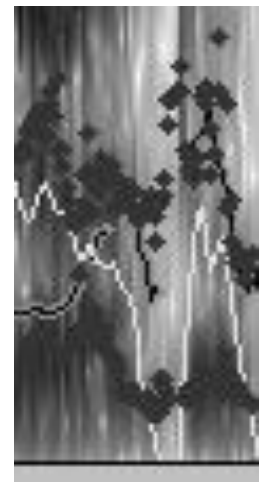




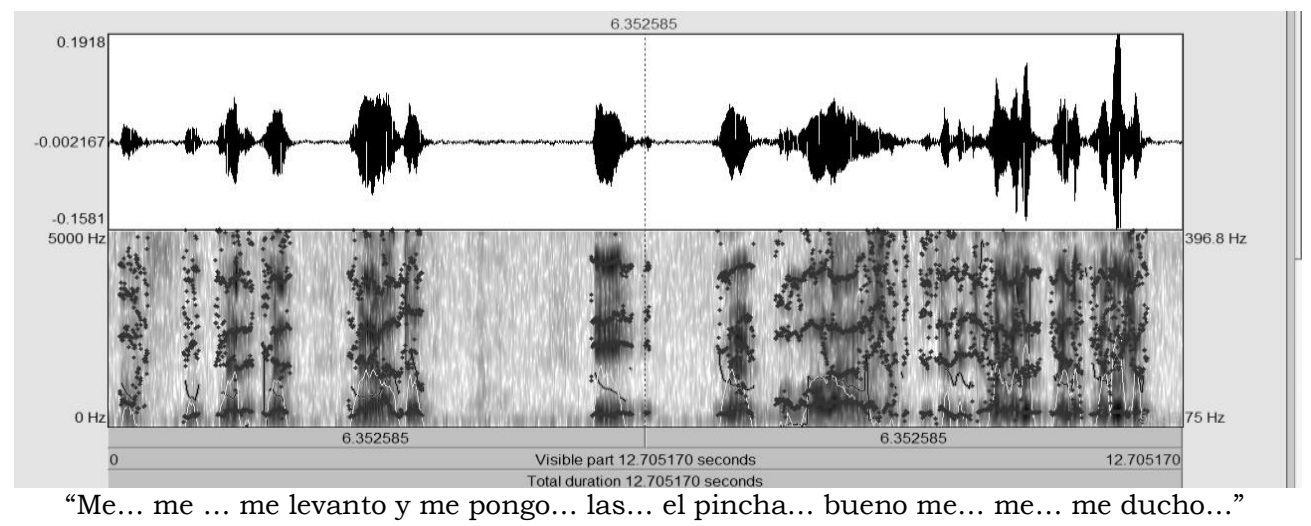

Intervención terapéutica: tras la evaluación vemos que los aspectos sobre los que hay que trabajar son: respiración, coordinación fonorrespiratoria, voz (uso de resonadores), ritmo de habla que mejore los aspectos prosódicos.

Puesto que las pruebas de gasometria indican que el rendimiento pulmonar es normal, la prioridad en el inicio del tratamiento es la normalización del funcionamiento respiratorio. Así, realizamos las siguientes acciones:

- Ejercicios de toma de conciencia de la respiración costodiafragmática y apoyo respiratorio con control postural.

- Usamos un inspirómetro trabajando por separado la inspiración y la respiración. Este instrumento permite un feed-back visual que refuerza la sensación de movimiento inspiratorio y espiratorio.

- Ejercicios Lax Vox. Lax Vox es una técnica de producción de voz con oclusión parcial y alargamiento del tracto vocal, que se usa con frecuencia en terapia y entrenamiento de la voz. El objetivo es producir un aumento en la impedancia de entrada del tracto vocal, efecto demostrado por Story et al. (2000: 456) y Laukkanen (1999: 151). Los tubos de resonancia se utilizan sumergiendo el extremo distal en agua, actuando como una extensión artificial del tracto vocal. Suelen utilizarse en casos de disfonía funcional. El efecto aerodinámico es el incremento del promedio de la presión supraglótica y por tanto un aumento de la presión intragolotal. Esto permite una separación de pliegues vocales, reduciendo el impacto mecánico al contactarse medialmente. Por su parte Titze (2007: 146-147) y Story et al. (2000: 454-455) señalan que un incremento en la reactancia por un estrechamiento en la zona baja del tracto vocal producirá un fortalecimiento de los armónicos altos, incluso un incremento en el nivel de presión de sonido, llevando esto a una producción más económica de la voz, mayor salida de sonido con menor estrés mecánico en los pliegues vocales. El aumento de la resistencia supraglótica es mayor con tubos de diámetro ancho $(1 \mathrm{~cm})$ frente a tubos de diámetro estrecho $(5 \mathrm{~mm})$.

- Ejercicios de ritmo con método del acento de Svend Smith: está dirigido a la mejora de la comunicación verbal en su conjunto, trabaja sobre la 
coordinación de la respiración, la fonación y la entonación melódica utilizando movimientos corporales rítmicos, la melodía y entonación melódica. Puesto que es un método integral, aborda la voz en aspectos tales como el tono, el timbre y la intensidad de forma simultánea. Se pretende con este método mejorar la producción de la voz y el habla en su conjunto. Se llevan a cabo ejercicios que aúnan la respiración con apoyo costodiafragmático adecuado, uso de movimientos rítmicos del cuerpo y/o manos/brazos, y acentuación de las vocales de forma suave y rítmica haciendo un juego rítmico corporal que se pasa de forma simultánea al habla continua. Pankas et al. (2011: 258) destacan que el éxito de este método está en la activación de funciones del habla en el cerebro y la toma de conciencia durante la ejecución. El movimiento rítmico permite una retroalimentación táctil y kinestésica constante que va ajustando el tempo, junto con el volumen, y la articulación del habla asociada al ritmo corporal. El método del acento subraya la importancia de la respiración en conexión con el movimiento y la fonación. Se basa en respiración costodiafragmática, e iniciamos los ejercicios con respiración sonora, utilizando sonidos fricativos sonoros, ajustados al ritmo corporal, en series de fonaciones cortas y largas. Los movimientos corporales asociados pueden abarcar el cuerpo en su globalidad si ello es necesario y posible, o solo movimientos con las piernas, los brazos o balanceo de la cabeza y tronco. Se trata de que el paciente imite la secuencia ritmica presentada por el terapeuta, como en un diálogo del tipo "ahora tu-ahora yo". Una vez realizada solo con sonidos fricativos sonoros, se pasa a ejercicios de habla conectada, con acentuación rítmica de vocales, o sílabas, y finalmente palabras con prosodia natural. Utilizamos al inicio expresiones comunes cortas, para pasar después a lectura en principio de poesía, por ser más rítmica en sí misma, a lectura de prosa, y finalmente descripción de situaciones, láminas y conversación espontánea.

Número de sesiones y frecuencia: el total de sesiones fue de 9. Durante tres semanas la frecuencia fue mayor, con dos sesiones semanales de 30 minutos de duración. Posteriormente disminuimos la frecuencia a una a la semana durante 2 semanas, cuando la ejecución no necesitaba tanto control por parte del terapeuta, y finalmente hicimos una última revisión al mes siguiente para comprobar la automatización e integración en el habla de lo trabajado.

\section{Valoración tras el tratamiento logopédico. Test de Robertson:}

Respiración y fonación: TMF $\mathrm{A}=12 \mathrm{sg}, \mathrm{S}=15 \mathrm{sg}$. El uso de resonadores ha aumentado desapareciendo el sonido parecido a frito vocal, y prácticamente ha desaparecido la constricción.

Diadococinesias y prosodia, prácticamente dentro de lo normal.

La colaboración y predisposición para la ejecución de ejercicios por parte del paciente ha sido excelente, lo que ha permitido una progresión adecuada.

Voice Handicap Index de Jacobson (1997): Funcional: 6, Físico: 5, Emocional: 7 . 
Escala de Inteligibilidad de Alteraciones Motoras del Habla (Duffy, 2005): nivel 9: a veces reducida frente a condiciones adversas cuando el contenido no tiene restricciones, pero adecuada al realizar reparos.

\section{Valoración acústica:}

Tras la intervención terapéutica (sesión del 7.11.2016) podemos observar en este caso que, si bien sigue habiendo pausas, la curva melódica no aparece tan entrecortada (es la prueba más evidente de que el método del acento ha funcionado), pero el tiempo de emisión de los sonidos sigue siendo breve; tampoco han variado la intensidad $(61.68 \mathrm{~dB}$ en la [á] de portando, en este caso) ni la conformación formántica de las vocales (los valores del F1 de [o]: $387.5 \mathrm{HZ}$ y de [á]: $606.5 \mathrm{HZ}$, si cabe más bajos que en el ejemplo anterior); las consonantes, en este caso $[\mathrm{p}]$, $[\mathrm{t}]$ y $[\delta]$, mantienen una ejecución "normal", aunque no se percibe barra de explosión, al menos en las sordas:
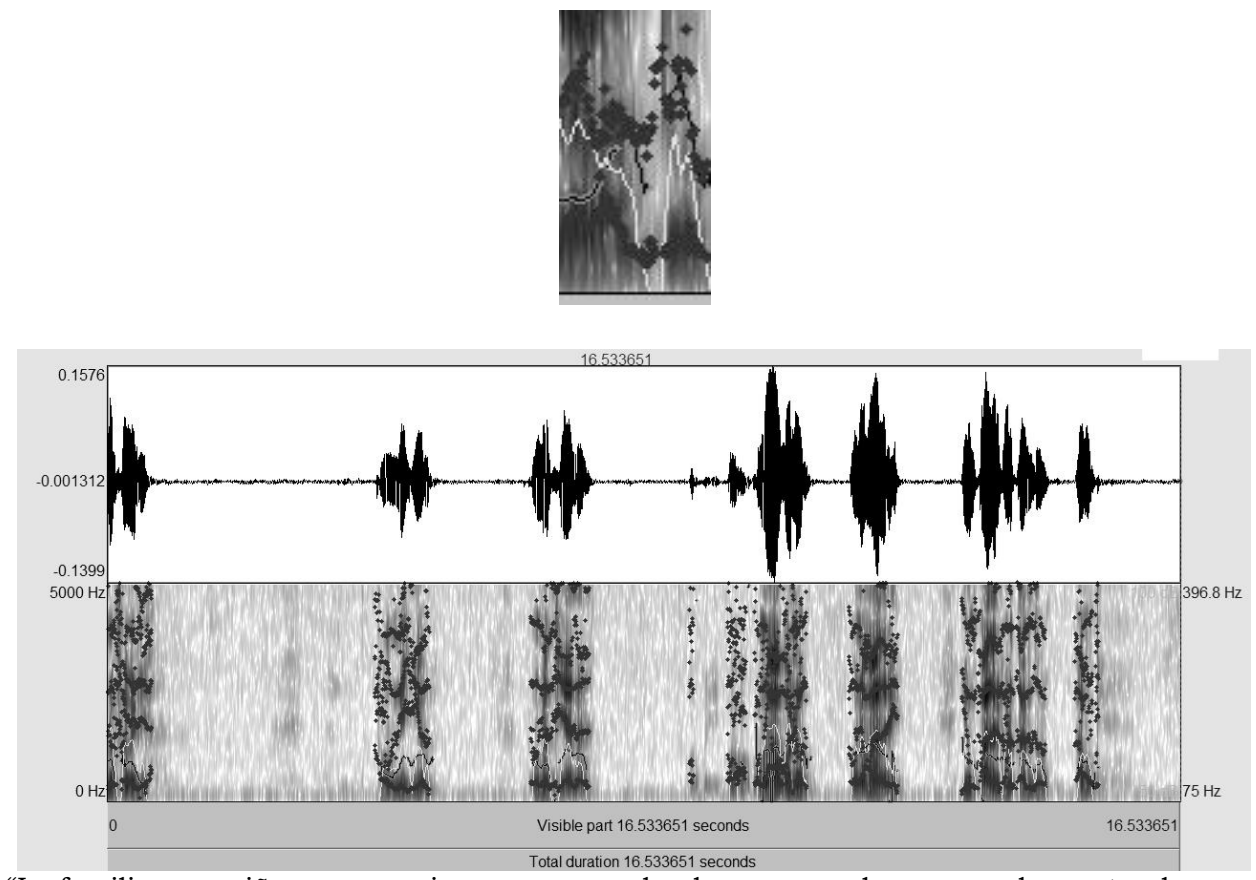

"La familia, con niños, una anciana... o unos abuelos, una madre y un padre portando... vamos..."

PACIENTE 2: C. O. G., de 63 años de edad, viuda, dedicada a las labores del hogar y con nivel medio de estudios (Educación Secundaria). En julio de 2015 habia presentado un infarto isquémico en territorio vertebro basilar, presentando parestesias en hemicuerpo derecho, rigidez en dedos de las manos y disfagia. La exploración con RMI de cráneo revela dos focos de aspecto isquémico en bulbo lateral izquierdo, con afectación focal de pedúnculo cerebeloso inferior izquierdo y depósito hemorrágico bulbar posterocentral asociado. Desde entonces presenta disfagia, sobre todo a líquidos. 
Acude a urgencias en septiembre de 2016 por presentar una alteración del lenguaje, siendo ingresada para estudio. Presenta buen estado general, consciente y orientada. Lenguaje normal, habla ligeramente disártrica. Exploración de pares craneales, fuerza, tono muscular de extremidades superiores dentro de la normalidad. En el estudio de imagen en esta ocasión con TAC se observa la lesión en pedúnculo cerebeloso izquierdo, acorde al episodio sufrido en julio de 2015, y sin signos de nuevo ACV. En estudios RMI posteriores confirma dos focos de aspecto isquémico en fase crónica con pequeño depósito hemorrágico asociado en territorio vértebro basilar (bulbo lateral izquierdo con afectación de pedúnculo cerebeloso inferior). Es dada de alta al día siguiente al ingreso, y remitida al servicio de Medicina Física y Rehabilitación para tratar la alteración del lenguaje mediante tratamiento logopédico.

En febrero de 2017 es valorada por FEA de Medicina Física y Rehabilitación y derivada a logopedia para tratamiento de la disartria y la disfagia.

\section{Valoración logopédica. Test de Robertson:}

- Respiración y fonación: presenta respiración torácica, ligera incoordinación fonorrespiratoria que afecta sobre todo a tomas de aire insuficientes. TMF $\mathrm{A}=8 \mathrm{sg}, \mathrm{S}=13 \mathrm{sg}$.

- Voz agravada y débil: bajo uso de resonadores, hacia el final de la nota llega a uso de frito vocal.

- Musculatura facial: no presenta alteración del tono muscular, pero hay ligera incoordinación de los movimientos que se le piden. Mejora la ejecución delante del espejo, gracias al control visual.

- Diadococinesias: ejecución con dificultades en el mantenimiento del ritmo, sin alteraciones en la articulación.

- Reflejos: no hay reflejo de naúsea, la tos no es fuerte, pero está presente. Presenta disfagia a líquidos para $10 \mathrm{ml}$ de agua, con voz húmeda, que mejora con cambio postural inclinando la cabeza hacia delante. Masticación adecuada y babeo ausente.

- Articulación: adecuada a la repetición.

- Prosodia: Habla ligeramente enlentecida, hipotónica y arrastrada.

Voice Handicap Index (Jacobson, 1997): Funcional: 26, Físico: 25, Emocional: 21.

Escala de Inteligibilidad de Alteraciones Motoras del Habla (Duffy, 2005): Nivel 6: a veces reducida en condiciones ideales cuando no existen restricciones de contenido, aun cuando se intenta realizar reparos.

\section{Análisis acústico previo:}

En el análisis que se realiza antes del tratamiento (sesión del 14.02.2017) se observa que el paciente presenta, quizá como resultado de no poder tragar bien, una curva melódica con pequeños altos y bajos -acompañada de un tiempo breve en la emisión de los sonidos-, una intensidad baja (61.40 dB en la [á] de garganta, que tomamos como referencia), y una conformación formántica cuyos valores corresponden más o menos a la media (el valor del F1 de [á]: $869.3 \mathrm{HZ}$ ). En cuanto a las consonantes teóricamente fuertes en 
la palabra garganta, la [t], si bien no muestra la barra de explosión, está claramente articulada, asi como las dos $[\gamma]$ :
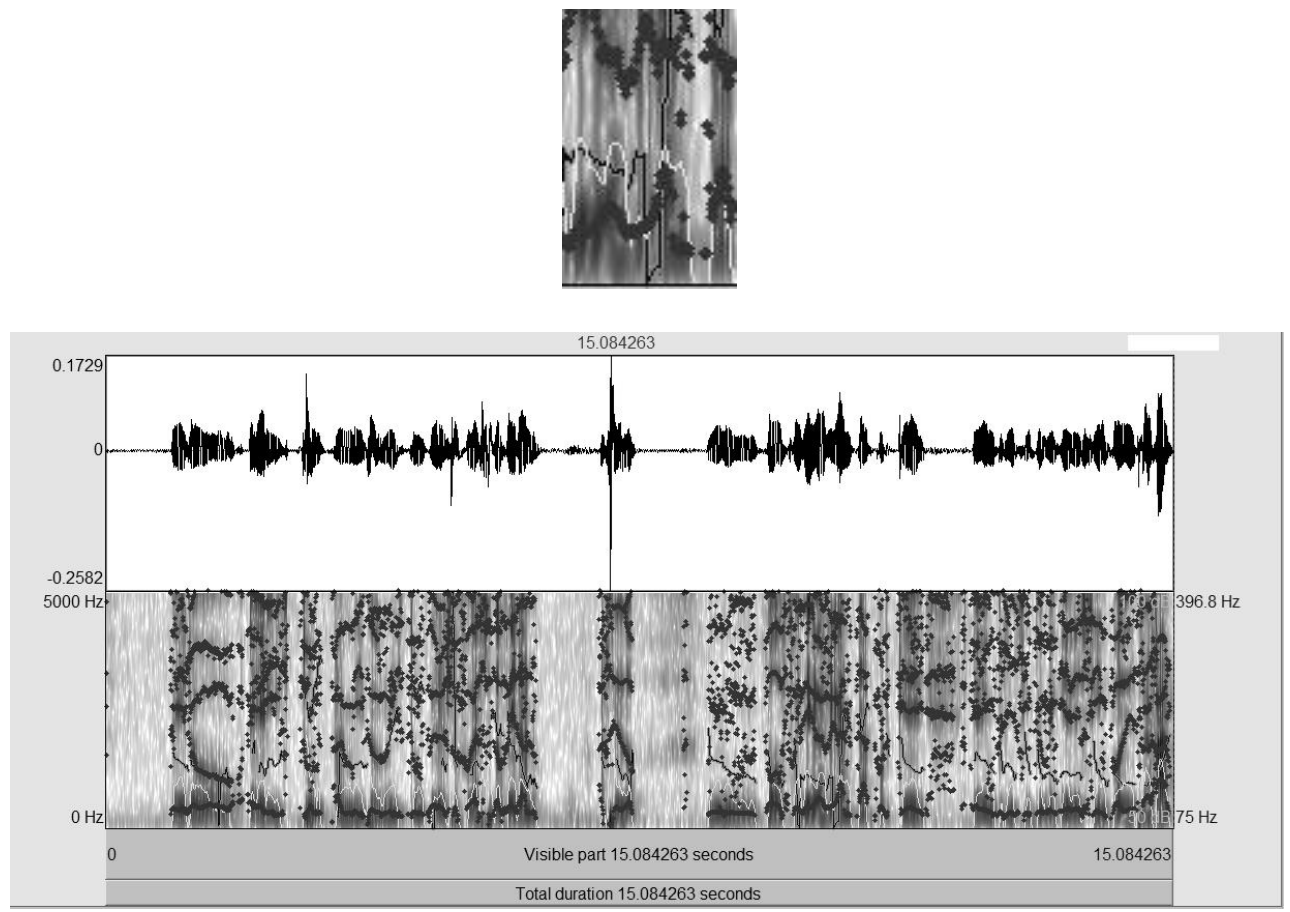

"Pero el ictus, a mi me dio un ictus, pero eso fue hace dos veranos, hace dos, todo fue de garganta porque en principio me quedé sin poder tragar..."

Intervención terapéutica: el tratamiento se plantea dirigido a mejorar respiración y la voz, mejorar la propioceptividad y coordinación de los movimientos del área orofacial, mejorar el ritmo de habla y lograr una deglución segura y eficaz. Las áreas de intervención son:

- Respiración: aprendizaje de respiración costodiafragmática con buen apoyo respiratorio. Trabajo sobre coordinación fonorrespiratoria con control de toma suficiente de aire y gestión adecuada del mismo.

- Ejercicios con Lax Vox (ya descrito anteriormente). En esta ocasión para mejorar el cierre glótico aumentamos la columna de agua que debe movilizar durante la fonación.

- Ejercicios con tracción lingual durante la ejecución de sílabas utilizando consonantes posteriores [k], [j] y con vocales [i], [e]. Durante la ejecución se trabaja el sonido "twang" para potenciar uso de resonadores.

- Ritmo y prosodia: lectura en voz alta con método del acento (ya descrito), primero con poesía, luego con prosa, descripciones de láminas y lenguaje espontáneo, para lograr mejorar el ritmo de habla coordinando respiración y entonación melódica. 
La colaboración y predisposición para la ejecución de ejercicios por parte de la paciente ha sido excelente, lo que ha permitido una progresión adecuada. Número de sesiones y frecuencia. El total de sesiones fue de 12, con una duración de 30 minutos cada una, durante tres semanas la frecuencia fue mayor, con dos sesiones semanales, posteriormente disminuimos la frecuencia a una a la semana durante 3 semanas, cuando la ejecución no necesitaba tanto control por parte del terapeuta, y finalmente hicimos una última revisión al mes siguiente para comprobar la automatización e integración en el habla de lo trabajado.

Valoración tras el tratamiento logopédico. Test de Robertson:

Respiración y fonación: TMF A= $12 \mathrm{sg}, \mathrm{S}=17 \mathrm{sg}$.

Ejecución de praxias orofaciales, diadococinesias y prosodia en valores próximos a la normalidad. Deglución dentro de la normalidad.

Voice Handicap Index (Jacobson, 1997): Funcional: 6, Físico: 7, Emocional: 5 .

Escala de Inteligibilidad de Alteraciones Motoras del Habla (Duffy, 2005): Nivel 9: a veces reducida en condiciones adversas cuando el contenido no tiene restricciones, pero adecuada al realizar reparos.

\section{Valoración acústica:}

Tras la intervención terapéutica (sesión del 4.04.2017) podemos observar una mayor claridad a la hora de articular; la curva melódica no tiene ya pequeños altos y bajos (aunque es una mujer que desde el principio mantuvo una curva melódica "funcional"), la intensidad se ha modificado algo (por ejemplo, hay $64.08 \mathrm{~dB}$ en la [é] de encuentro, que hemos tomado como referencia), pero no hay grandes cambios en la conformación formántica de las vocales (los valores del F1 de [é]: $431.3 \mathrm{HZ}$ y de [o]: 475.1), y las consonantes $[\mathrm{k}]$ y $[\mathrm{t}]$ mantienen una ejecución "normal", aunque sin barra de explosión:

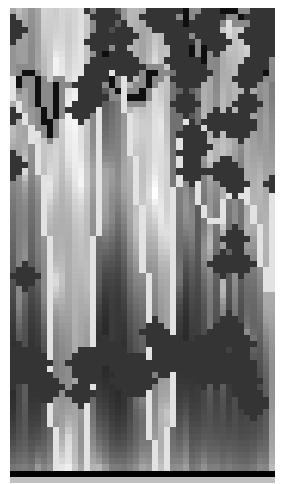




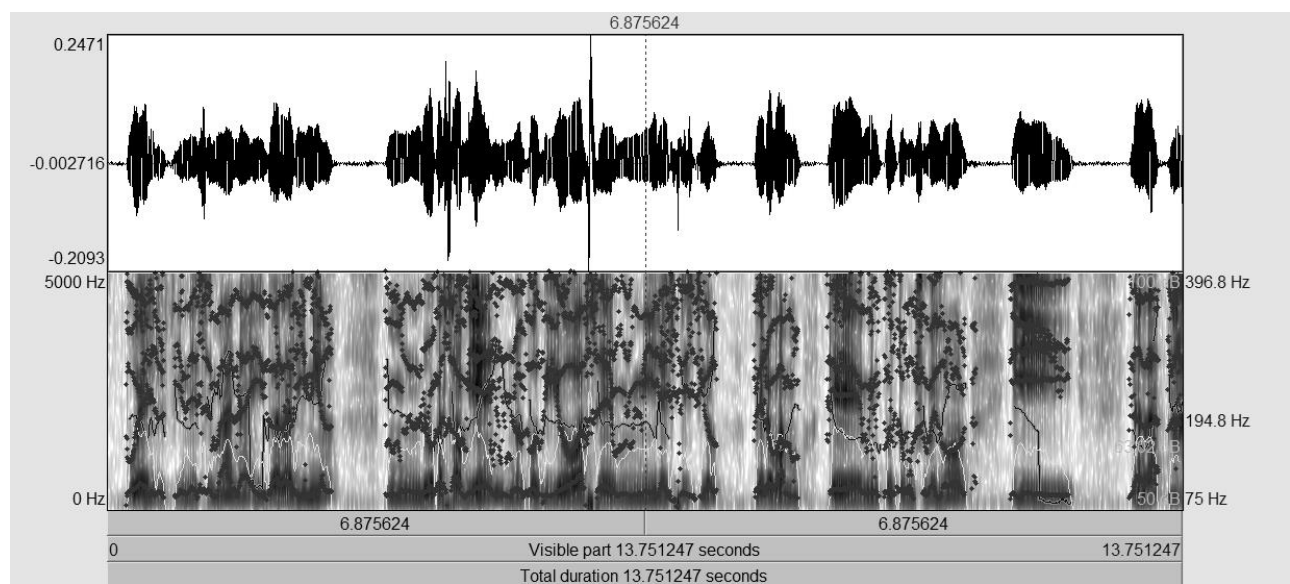

"Pues el fin de semana he ido a La Línea, lo he pasao bien, no he podío hacer mis ejercicios, pero, vamos, que me encuentro mucho mejor y... nada"

PACIENTE 3: F. G. O., entre de 67 años, natural de Chiclana de la Frontera (Cádiz), donde actualmente reside, jubilado, ha sido docente en un colegio de primaria. Acude a urgencias de nuestro hospital por disartria severa y pérdida de fuerza en hemicuerpo derecho de manera brusca, aunque en las semanas anteriores ha tenido episodios repetitivos de disartria autolimitado a minutos.

La exploración neurológica muestra hemiparesia derecha grado 4/5 y disartria. En el estudio radiológico con TC sin contraste IV de cráneo se ve lesión isquémica aguda/subaguda en el territorio de la arteria cerebelosa superior, con lesión isquémica aguda/subaguda cerebelosa superior derecha. Es dado de alta en el hospital el 31 de agosto. Acude a consulta del servicio de Medicina Física y Rehabilitación en la semana siguiente para iniciar tratamiento rehabilitador. La exploración en rehabilitación: sin aparente deterioro cognitivo, disartria, disfagia ocasional a liquidos, marcha inestable con aumento de la base de sustentación.

Diagnóstico en rehabilitación: Ataxia y disartria. Es incluido en tratamiento rehabilitador de fisioterapia para mejorar marcha y en tratamiento rehabilitador de logopedia para mejorar habla y deglución.

\section{Valoración logopédica. Test de Robertson:}

- Respiración y fonación: respiración torácica, inadecuada gestión de la coordinación fonorrespiratoria leve con tomas de aire insuficientes. Voz ocasionalmente nasalizada. TMF $A=3 \mathrm{sg}, \mathrm{S}=6 \mathrm{sg}$. Dificil evaluación, no se logra que haga una ejecución adecuada, termina antes de agotar el aire tanto en fonación como en respiración.

- La voz es engolada, pero el tono y el uso de resonadores es adecuado, articulación lenta y desdibujada.

- Musculatura facial: ejecución de praxias con falta de armonía y coordinación. No alteración de tono muscular. Mejora con control visual.

- Diadococinesias: ejecución lenta y no puede mantener el ritmo. 
- Prosodia: ritmo de habla enlentecido, con entonación adecuada.

Voice Handicap Index de Jacobson (1997): Funcional: 38, Físico: 30, Emocional: 21 .

Escala de Inteligibilidad de Alteraciones Motoras del Habla (Duffy, 2005): Nivel 4: usualmente reducida bajo condiciones adversas, cuando el contenido no tiene restricciones, aun cuando se intenta realizar reparos.

\section{Análisis acústico previo:}

En el análisis que se realiza antes del tratamiento (sesión del 10.01.2017) se observa que el paciente presenta, por problemas respiratorios, una curva melódica con tiempo lento, aunque "funcional", una intensidad media (65.53 $\mathrm{dB}$ en la [á] de martes, que tomamos como referencia), y una conformación formántica cuyos valores corresponden más o menos a la media (el valor del F1 de [á]: $891.2 \mathrm{HZ}$ y el de [e] de $409.4 \mathrm{HZ}$ ). En cuanto a las consonantes teóricamente fuertes en la palabra martes, la [t], si bien no muestra la barra de explosión, está claramente articulada, no así la [s], que desde el punto de vista perceptivo no es audible, aunque sí se observa un breve ruido de fricción al final:
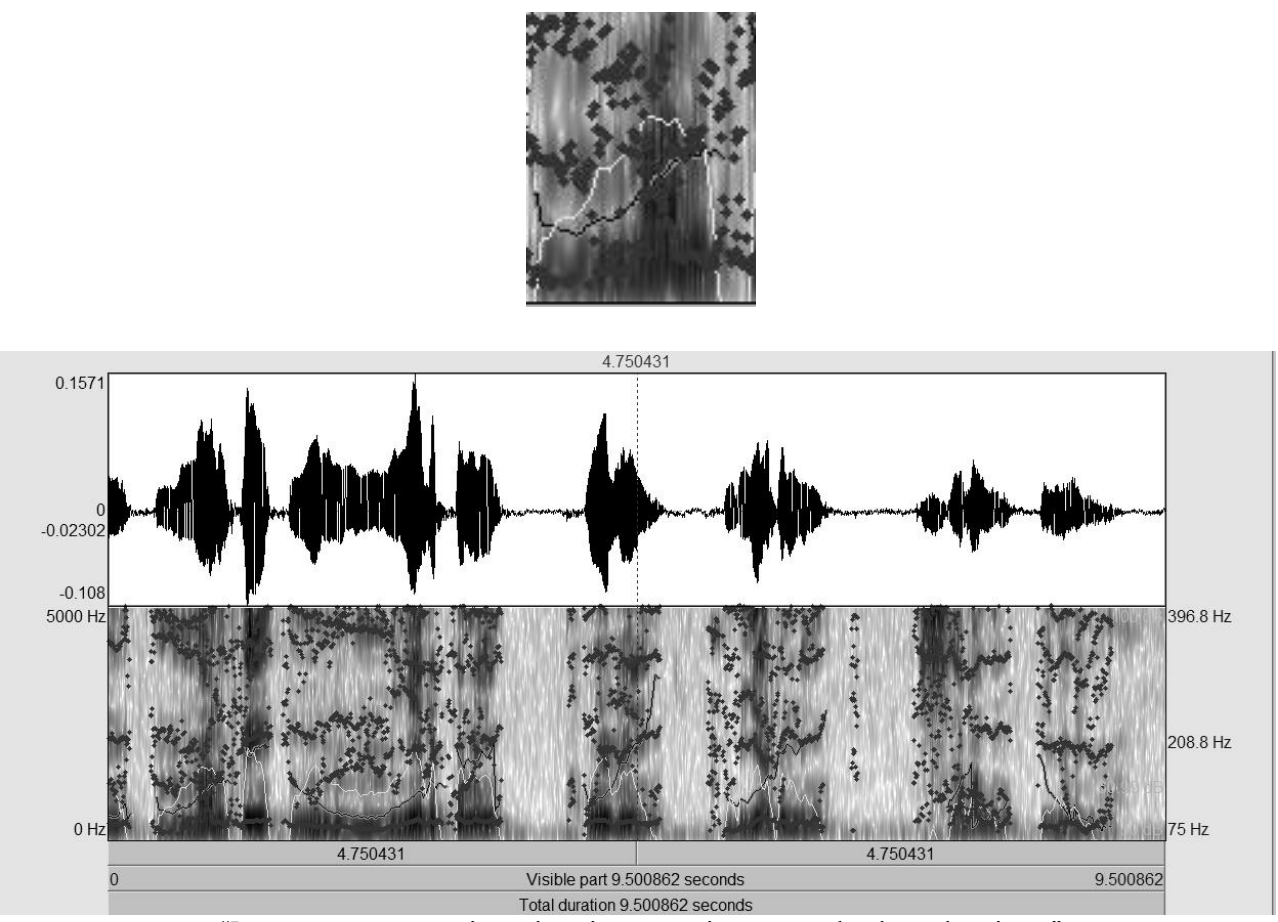

"Lunes, martes, miércoles, jueves, viernes, sábado y domingo"

Intervención terapéutica: los objetivos de tratamiento son mejorar la respiración, la voz y la coordinación fonorrespiratoria, mejorar el control de 
movimientos de musculatura orofacial aumentando la propiocepción, mejorar la inteligibilidad en el habla encadenada, y lograr una deglución segura y eficaz. Las áreas de intervención han sido:

- Respiración y fonación: ejercicios de respiración costodiafragmática y apoyo respiratorio. Es dificil lograr buen apoyo sobre todo al principio del tratamiento al encontrarse en silla de ruedas, por lo que el control postural se dificulta. Se va logrando en colaboración con la fisioterapeuta que lleva la rehabilitación postural en el gimnasio del hospital. Intentamos ejercicios de lax vox, pero debido a la falta de control postural inicial se observa tendencia a la constricción laringea durante su ejecución, por lo que anulamos este ejercicio.

- Motricidad orofacial: ejecución de praxias con control visual para aumentar la propioceptividad y mejorar la ejecución coordinada de los movimientos labio-linguales. El paciente utiliza prótesis dental pero no está bien sujeta, por lo que la ejecución de los movimientos sobre todo de lengua se ve entorpecida. Se solicita al familiar que se haga buena sujeción de la prótesis dental, pero no siempre es adecuada.

- Ritmo: utilizamos método del acento (ya descrito) en lectura primero de poesía, luego de prosa, descripción de láminas y conversación espontánea.

- Ejercicios de entonación melódica, exagerando la articulación palabra a palabra, con ayuda de un metrónomo, primero en series automáticas, luego poesía.

Durante las sesiones de logopedia, su mujer le acompaña siempre. El paciente se muestra cansado y con pocas ganas de hacer los ejercicios. Es su mujer quien lo alienta y ayuda con la ejecución. En casa es ella quien plantea la programación de la ejecución de los ejercicios, y en las sesiones se queja de que le cuesta mucho que se ponga a hacerlos en casa.

Número de sesiones y frecuencia: el total de sesiones fue de 20. Durante 5 semanas la frecuencia fue de dos sesiones semanales. Posteriormente disminuimos la frecuencia a una a la semana durante 8 semanas, siendo la asistencia irregular. El paciente es inconstante en la ejercitación, es su mujer quien supervisa e insiste en la ejercitación en casa. Esto provoca que la automatización se vea dificultada. El proceso de mejoria se estanca, por lo que damos el alta, con la recomendación de seguir ejercitando para lograr automatización.

\section{Valoración tras el tratamiento logopédico. Test de Robertson:}

- Respiración y fonación: TMF A= $6 \mathrm{sg}, \mathrm{S}=10 \mathrm{sg}$.

- Motricidad orofacial: el control de los movimientos es mejor, no necesita espejo para la ejecución. Aún presenta ligera incoordinación.

- Diadococinesias: de ejecución lenta y con mejor coordinación.

- Articulación: es más amplia, con más conciencia en los movimientos. Aún arrastra algunos sonidos.

- Prosodia: ha mejorado el ritmo logrando mejor inteligibilidad. 
Voice Handicap Index de Jacobson (1997): Funcional: 14, Físico: 12, Emocional: 16.

Escala de Inteligibilidad de Alteraciones Motoras del Habla (Duffy, 2005): Nivel 7: a veces reducida frente a condiciones adversas aun cuando el contenido está restringido, pero adecuada al realizar reparos.

\section{Valoración acústica:}

Tras la intervención terapéutica (sesión del 8.02.2017) podemos observar en este caso que, si bien sigue habiendo pausas, la curva melódica no aparece tan entrecortada, ya que la respiración ha mejorado, aunque las pausas siguen siendo considerables y el tiempo de emisión de los sonidos breve; tampoco han variado la intensidad (60.95 dB en la [á] de trabajo, en este caso) ni la conformación formántica de las vocales (los valores del F1 de [á]: 672.2 $\mathrm{HZ}$-más baja que en la ejecución anterior- y de [o]: $497 \mathrm{HZ}$ ); las consonantes, en este caso [t], [ß] y [x], mantienen una ejecución "normal", aunque sin presencia de barra de explosión:
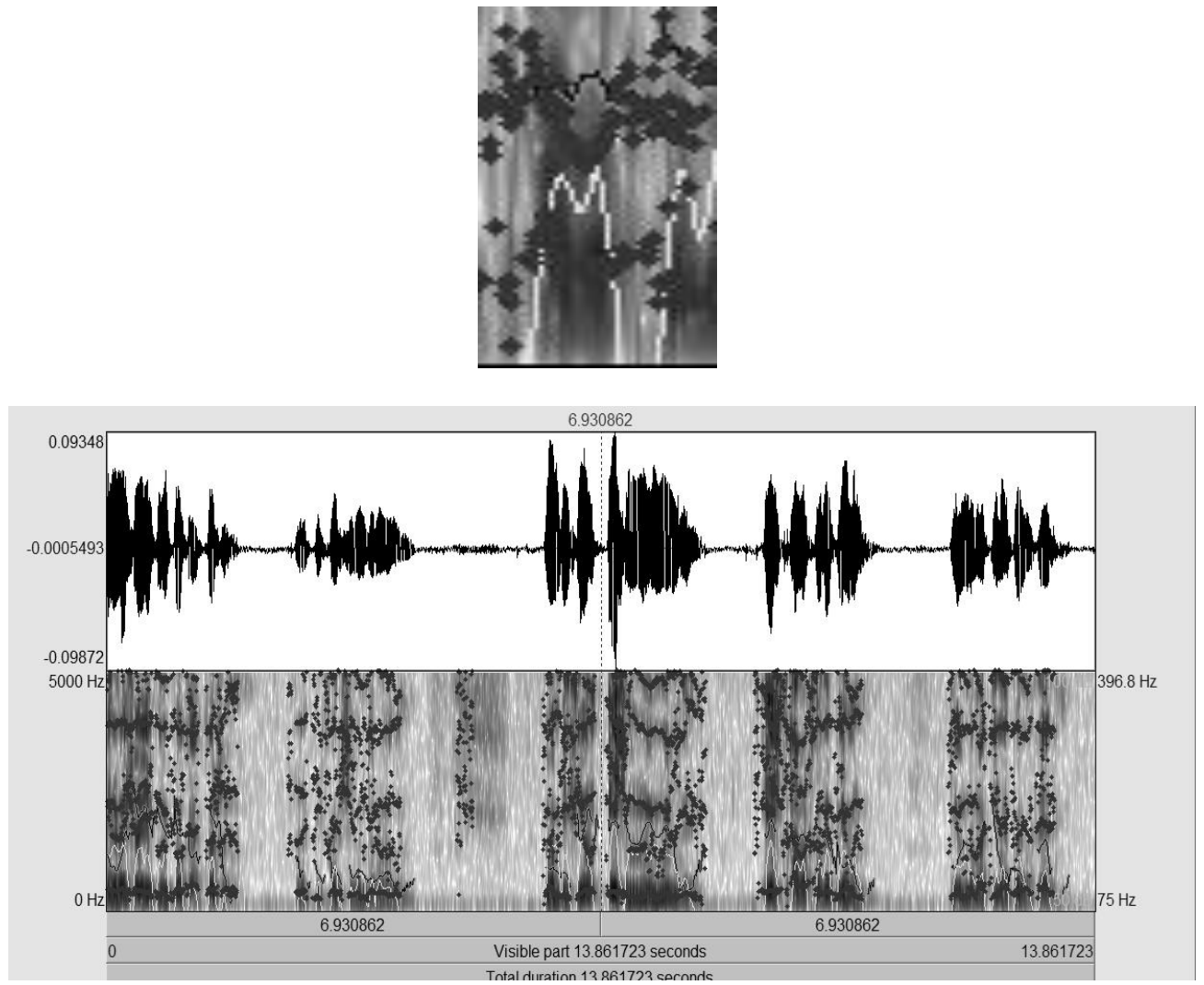

"Pero eso es poca cosa, le dijo el segundo albañil, tu ambición es muy humilde, es trabajo de peón, que una máquina puede hacer..." 


\section{4. ¿SE PUEDE GENERAR UNA TÉCNICA DE ANÁlISIS ACÚSTICO A PARTIR DE UNOS PATRONES SOBRE LOS QUE INCIDIR?}

La critica que habitualmente se hace a instrumentos como la herramienta informática Praat en el ámbito de la Logopedia viene determinada por la ausencia de estandarización que permita establecer datos de "normalidad" y de patologia, aunque ya hemos reflexionado sobre lo que implica el concepto de normal y de funcional en el campo de la voz y el habla.

Teniendo en cuenta, como se ha detallado al comienzo, que la disartria tiene básicamente repercusiones en la respiración y que se ven afectados, como también se ha comentado en el "Análisis acústico previo" y en la "Valoración acústica", la curva melódica, la intensidad, la duración y, en menor medida, la función que tienen que cumplir los resonadores, esos parámetros no solo pueden comprobarse a través de Praat sino que puede hacerse un seguimiento de ellos.

Al poder hacer tal seguimiento, a partir de la observación de algunos casos clínicos, parece de rigor hacernos la pregunta que da título a este apartado: ¿se puede generar una técnica de análisis acústico a partir de unos patrones sobre los que incidir? Aunque el término técnica pueda implicar un procedimiento exhaustivo, planteariamos solo un seguimiento que fuera controlando, como hemos citado, la curva melódica, la intensidad, la duración y, si fuera necesario, la función de los distintos resonadores (en este último caso habria que valorar la tonicidad de la musculatura orofacial, sobre todo). Y esa "técnica" es factible si la entendemos como una herramienta de control, es decir, como una herramienta que permita al especialista incidir en aquellos parámetros que, tras algunas sesiones, vea deficitarios.

En este sentido, consideramos que con el programa informático Praat, que permite una visual de la voz y el habla, el logopeda puede "interactuar" también con el programa, observando aquellos valores sobre los que todavía no se ha producido ningún o escaso progreso, y trabajando más en ellos con el paciente. Para ello es necesario un perfecto conocimiento de esta herramienta informática.

\section{Conclusiones}

Después de todo lo expuesto, podemos concluir que:

- El método del acento es muy efectivo porque actúa integrando parámetros como respiración, articulación, ritmo, que se traducen en una mejor ejecución de la curva melódica, del tiempo de emisión de los sonidos y, en definitiva, en la consecución de una voz más "funcional";

- El paciente y el interlocutor perciben la mejoría, con lo cual el paciente se siente más cómodo y motivado y la inteligibilidad en todos los ámbitos mejora con vistas a la comunicación; 
Incidiendo especialmente en el protocolo que se sigue en la rehabilitación, así como en el seguimiento a través de Praat, este estudio sugiere que sería conveniente establecer un protocolo consistente exactamente en la regularidad de la técnica, es decir, en recoger la misma muestra de producción oral del paciente antes, durante y después de la rehabilitación logopédica que nos permita comparar parámetro en esos tres estadíos e incidir en la mejora de aquellos que sigan siendo deficitarios.

\section{REFERENCIAS}

ARONSON, A. E. (1990): Clinical voice disorders. An interdisciplinary approach, New York: Thieme Inc.

CANNITO, M. \& MARQUARDT, T. P. (1997): "Ataxia dysarthria", McNeil, M. R. (ed.): Clinical management of sensorimotor speech disorders, New York: Thieme Inc., pp. 217-249.

COBETA, I. et al. (2013): "Voz normal y clasificación de las disfonías", Patología de la voz (Ponencia oficial de la SEORL y PCF), Barcelona: Ed. Marge médica books, pp. 237-242.

DARLEY, F. L. et al. (1975): Audio seminars in speech pathology: Motor speech disorders, Philadelphia: WB Saunders, pp. 268-275.

DUFFY, J. R. (2005): Motor speech disorders: substrates, differential diagnosis, and management, Philadelphia: Elsevier Mosby, pp. 379-443.

LAUKKANEN, A. M. (1992): "About the so called "resonance tubes" used in Finnish voice training practice. An electroglottographic and acoustic investigation on the effects of this method on the voice quality of subjects with normal voice", Scandinavian Journal of Logopedics and Phoniatrics, 17 (4), pp. 151-161.

LLAU ARCUSA, M. J. y GONZÁLEZ ÁLVAREZ, J. (2004): "Medida de la inteligibilidad en el habla disártrica", Revista de Logopedia, Foniatría y Audiología, 24 (1), pp. 33-43.

MELLE, N. (2003): "Disartria en el daño cerebral adquirido: hacia un método global de evaluación", Revista de Logopedia, Foniatria y Audiología, 23 (1), pp. 20-29.

MELLE, N. (2007a): Guía de intervención logopédica en la disartria, Madrid: Síntesis.

MELLE, N. (2007b): "Intervención logopédica en la disartria", $R e$ vista de Logopedia, Foniatría y Audiología, 27 (4), pp. 187-197.

MELLE, N. (2012): "Disartria. Práctica basada en la evidencia y guias de práctica clínica", Revista de Logopedia, Foniatría y Audiología, 32, pp. 120-133.

MOORE, J. P. (1971): Organic voice disorders, Englewood Cliffs: Prentice-Hall.

NÚÑEZ-BATALLA, F. et al. (2007): "Adaptación y validación del índice de incapacidad vocal (VHI30) y su versión abreviada (VHI10) al español", Acta Otorrinolaringológica Española, 58 (9), pp. 386-392.

PANKAS, J. et al. (2011): "Importance of correct therapeutic procedure selection in voice recovery", Coll Antropol, 35 (2), pp. 259-262. 
QUILIS, A. (1981): Fonética acústica de la lengua española, Madrid: Gredos.

SELLARS, C. et al. (2007). "Terapia del habla y del lenguaje para la disartria por daño cerebral no progresivo", La Biblioteca Cochrane Plus, 4, Oxford: Update Software Ltd.

STORY, B. et al. (2000): "Acoustic impedance of an articially lengthened and constricted vocal tract”, J Voice, 14 (4), pp. 455469.

TITZE, I. (2006): "Voice training and therapy with a semi- occluded vocal tract: rationale and scienti c underpinnings", J Speech Lang Hear Res., 49 (2), pp. 448-
459.

TITZE, I. \& LAUKKANEN, A. (2007): "Can vocal economy in phonation be increased with an arti cially lengthened vocal tract? A computer modeling study", Logoped Phoniatr Vocol, 32 (4), pp. 147-156.

WORRAL, L. E. (2000): “A concpetual framework for a functional approach to acquired neurogenic disordres of communication and swallowing", Worral, L. E. \& Frattali, C. M. (eds.): Neurogenic Communication Disorderes: a functional approach, New York: Thieme, pp. 3-39. 